\title{
Synthesis of selected azoles derivatives using the cross-combination of microwave and ultrasound factors ${ }^{+}$
}

\author{
Anna Pawełczyk*, Katarzyna Sowa-Kasprzak and Lucjusz Zaprutko \\ Poznan University of Medical Sciences, Pharmaceutical Faculty, Department of Organic Chemistry, \\ Grunwaldzka 6, Poznań, Poland \\ * Correspondence: apaw@ump.edu.pl; Tel.: +48-61-854-6672 \\ + Presented at the title, place, and date.
}

Academic Editor: name

Received: date; Accepted: date; Published: date

\begin{abstract}
Comparative study of various activating factors for obtaining derivatives of pyrazole and isoxazole systems were described, including microwave, ultrasonic action and SMUI methods. Reactions using the appropriate $\beta$-dicarbonyl compounds with hydrazine or hydroxylamine reached completion in 5-10 minutes. The next $\beta$-dicarbonyl structure modified under SMUI conditions was curcumin, natural compound that is a candidate for therapeutic use. The pyrazole and isoxazole heterocyclic derivatives of curcumin were obtained in a short time 10-20 minutes. Both microwave and ultrasonic factors promoted heterocyclization, but the use of SMUI proved to be fundamental for reducing the reaction time.
\end{abstract}

Keywords: azoles, pyrazole, isoxazole, curcumin, microwave, ultrasounds, SMUI

\section{Introduction}

Azoles are a class of five-membered heterocyclic compounds containing a nitrogen atom and at least one other non-carbon atom $(\mathrm{N}, \mathrm{S}$ or $\mathrm{O})$ as part of the ring. Azoles include pyrazole and oxazole systems, which are potent medicinal scaffolds exhibiting a full spectrum of biological activities. Pyrazoles are reported to possess anti-microbial, anti-fungal, anti-tubercular, anti-inflammatory, anti-convulsant, anti-cancer and anti-viral activity [1]. Isoxazole derivatives show hypoglycemic, analgesic, anti-inflammatory, anti-fungal, anti-bacterial and HIV-inhibitory activities [2]. The substituted azoles are also considered to be important synthons due to their versatility in terms of chemical transformations to useful synthetic intermediates. Importance of research on azole moiety has already been proven by various research groups in the literature. Many procedures are established for the synthesis of azole core, but very few of them lead to azole with better yields [2-4]. Among the most widespread synthetic strategies for obtaining selected azoles structures are the reaction of $\beta$-dicarbonyl compounds with hydrazines or hydroxyloamine [5], which lead to pyrazole and isoxazole systems respectively.

In recent times the environmental impact has become very important in the design of new synthetic methodologies in organic and medicinal chemistry. One of the most preferred applications in the field of heterocyclic chemistry is the microwave-assisted technique [6]. Ultrasound is also employed to promote the synthesis of different azole derivatives [7]. The use of these alternative activation factors, microwaves or ultrasounds and also their mutual cross-combination (SMUI Simultaneous Microwave and Ultrasound Irradiation) has become very promising and desirable synthetic methodologies in efficient and fast formating of structures [8]. Microwave heating and ultrasonic waves, both of which are green techniques, are among the simplest, least expensive and most valuable tools in applied chemistry. To demonstrate the general applicability of this combined 
green, energy-saving method, a series of pyrazole and isoxazole derivatives has been synthesised under SMUI conditions.

\section{Materials and Methods}

MW, US and SMUI mode reactions were conducted in an automatic microwave UWave-1000 Sineo Reactor equipped with an immersion ultrasound probe and a UV lamp (MW: 0-1000W, US: 0800W, UV: $365 \mathrm{~nm}, 300 \mathrm{~W}$, IR and Pt temperature sensor, stirrer). Reactions of appropriate $\beta$ dicarbonyl compounds with hydrazine or hydroxylamine were conducted using three modes: microwave irradiation (MW), ultrasonic action (US) and the SMUI method. The pyrazole and isoxazole derivatives of $\beta$-dicarbonyl compounds were prepared as presented in Scheme 1.<smiles>CCOC(=O)CC(C)=O</smiles>

Scheme 1. Heterocyclization of $\beta$-dicarbonyl compounds. Reagents and conditions: $\mathrm{NH}_{2} \mathrm{NH}_{2} \cdot \mathrm{H}_{2} \mathrm{O}$ (for 3 and 4 ) $\mathrm{NH}_{2} \mathrm{OH} \cdot \mathrm{HCl}$ (for 5 and 6), $\mathrm{EtOH}, \mathrm{K}_{2} \mathrm{CO}_{3}$

Based on good results of the above reactions, the next $\beta$-dicarbonyl structure modified to heterocyclic derivatives under SMUI conditions was curcumin, a natural compound that is a candidate for therapeutic use. The pyrazole and isoxazole derivatives of curcumin were prepared as presented in Scheme 2.<smiles>CCCCCCCc1cc(/C=C/c2ccc(O)c(OC)c2)on1</smiles><smiles>COc1cc(/C=C/C(=O)CC(=O)/C=C/c2ccc(O)c(OC)c2)ccc1O</smiles><smiles>COc1cc(/C=C/c2cc(/C=C/c3ccc(O)c(OC)c3)[nH]n2)ccc1O</smiles>

Scheme 1. Heterocyclization of curcumin $\beta$-dicarbonyl moiety. Reagents and conditions: $\mathrm{NH}_{2} \mathrm{NH}_{2} \cdot \mathrm{H}_{2} \mathrm{O}$ (for 8 ) $\mathrm{NH}_{2} \mathrm{OH} \cdot \mathrm{HCl}$ (for 9), $\mathrm{EtOH}, \mathrm{K}_{2} \mathrm{CO}_{3}$

\section{Results and Discussion}

One of the methods of obtaining pyrazole and isoxazolone systems is through reacting $\beta$ dicarbonyl compounds, e.g. suitable diketone or diketoesters with derivatives of hydrazine and hydroxylamine (Scheme 1). For simple diketones, the reaction is relatively easy, although under conventional conditions, it takes several hours of heating [5]. In 2010 both ultrasounds and 
microwaves were employed separately to promote the synthesis of pyrazolones in the reaction of $\beta$ ketoesters with hydrazine derivatives in ethanol. The reaction reached completion in a short time (5$25 \mathrm{~min}$ ) and produced main products with good yields [9]. A series of isoxazole derivatives were prepared by ultrasound-promoted cyclization in shorter times than the corresponding classical reaction [10]. In 2009, a scaled-up sonochemical method of acetylacetone conversion to simply pyrazole and isoxazole in aqueous media was described. The products were obtained after 10 minutes of sonification, compared to 12 hours' heating without ultrasound [7]. As outlined in Scheme 1 two 1,3-dicarbonyl reagents (diketone and ketoester) were reacted with hydrazine or hydroxyloamine respectively using three different reaction-activating procedures: ultrasounds (US), microwave irradiation (MW) and simultaneous action of microwave irradiation and ultrasound waves (SMUI). The results of these reactions are summarized in Table 1, which includes the time, temperature and yield of the main product.

Table 1. The main parameters of heterocyclization reaction

\begin{tabular}{|c|c|c|c|c|c|c|c|c|}
\hline \multirow{2}{*}{ 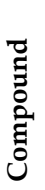 } & \multicolumn{2}{|c|}{ Reflux $^{* 1}$} & \multicolumn{2}{|c|}{ US $^{* 2}$} & \multicolumn{2}{|c|}{$\mathrm{MW}^{* 3}$} & \multicolumn{2}{|c|}{ SMUI $^{* 4}$} \\
\hline & $\underset{\Xi}{\Xi}$ & 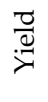 & 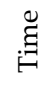 & $\underset{\nabla}{\stackrel{\vec{d}}{\nabla}}$ & $\underset{\Xi}{\Xi}$ & $\stackrel{\vec{Z}}{\stackrel{\nabla}{\nabla}}$ & $\underset{\Xi}{\Xi}$ & 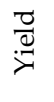 \\
\hline 3 & $6 \mathrm{~h}$ & 73 & 10 & 57 & 10 & 68 & 5 & 83 \\
\hline 4 & $6 \mathrm{~h}$ & 77 & 10 & 62 & 10 & 71 & 5 & 81 \\
\hline 5 & $8 \mathrm{~h}$ & 56 & 10 & 35 & 10 & 72 & 5 & 84 \\
\hline 6 & $8 \mathrm{~h}$ & 45 & 10 & 42 & 10 & 64 & 5 & 80 \\
\hline 8 & $24 \mathrm{~h}$ & - & 60 & - & 20 & 15 & 10 & 64 \\
\hline 9 & $24 \mathrm{~h}$ & - & 60 & - & 20 & 20 & 10 & 52 \\
\hline
\end{tabular}

Diketone 1 and ketoester 2 was reacted in a short time and with good yields. In comparison, $(1 E, 6 E)$ 1,7-bis(4-hydroxy-3-methoxyphenyl)hepta-1,6-diene-3,5-dione (7), commonly called curcumin, was less reactive under the experimental conditions. Curcumin is a potent natural compound that is a candidate for many therapeutic uses. In our experiment, the pyrazole and isoxazole heterocyclic derivatives of curcumin were obtained in a very short time - 10-20 minutes - with a good yield. Using the classical methods, curcumin was converted into its pyrazole derivative 8 with a hydrazine hydrate in acetic acid at room temperature in 8 hours [11]. The isoxazole derivatives of curcumin were obtained in a reaction with hydroxyamine hydrochloride, pyridine in ethanol at reflux for 18 hours [11]. Using the SMUI method the pyrazole and isoxazole derivatives of curcumin were obtained in a much shorter time - 10-20 minutes - with a good yield.

As a result of using a cross-combination of microwaves and ultrasound factors azole derivatives of respective 1,3-diketones were prepared. Pyrazole and isoxazole derivatives of 2,4-pentadione, ethyl 1,3-oxobutanoate and curcumin in particular were obtained in time- and energy-saving manner consistent with the guidelines of Green Chemistry. All the compounds obtained confirmed the literature data $[7,9,11]$.

\section{Conclusions}

The SMUI method provides highly efficient microwave dielectric heating and ultrasound cavitation phenomena, resulting in an enhanced reaction rate, and a reduction in energy for chemical transformation. On the example of the above heterocyclization reaction, SMUI was found to be the most efficient activating factor, followed by microwave and ultrasonic mode. Both microwave and ultrasonic factors promoted the heterocyclization reaction, but the use of SMUI proved to be fundamental for reducing the reaction time. All compounds were obtained using a time- and energysaving green method. This is a particularly valuable method for obtaining curcumin derivatives, which do not always show clear reactivity. 
Author Contributions: A.P and L.Z. conceived and designed the experiments; A.P. and K.S.K. performed the experiments; A.P. wrote the paper.

Conflicts of Interest: The authors declare no conflict of interest

\section{References}

1. Naim, M.J.; Alam, O.; Nawaz, F.; Alam, M.J.; Alam, P. Current status of pyrazole and its biological activities. J. Pharm. Bioallied. Sci. 2016, 8(1), 2-17.

2. Pinho e Melo, T. M. V. D. Recent Advances on the Synthesis and Reactivity of Isoxazoles. Curr. Org. Chem. 2005, 9, 925-958. DOI: 10.2174/1385272054368420.

3. Kost, A. N.; Grandberg, I. I. Progress in Pyrazole Chemistry. Adv. Heterocycl. Chem. 1966, 6, 347-429. DOI: 10.1016/S0065-2725(08)60579-6.

4. Aggarwal, V. K.; de Vicente, J.; Bonnert R. V. A Novel One-Pot Method for the Preparation of Pyrazoles by 1,3-Dipolar Cycloadditions of Diazo Compounds Generated in Situ. J. Org. Chem. 2003, 68, 5381-5383. DOI: $10.1021 /$ jo0268409.

5. Joule, J. A.; Mills, K. 1,2-Azoles and 1,3-Azoles, in Heterocyclic Chemistry at a Glance. 2nd ed.; John Wiley \& Sons, Ltd, Chichester, UK, 2012. ISBN: 978-1-4051-3300-5.

6. Majumder, A.; Gupta, R.; Jain, A. Microwave-assisted synthesis of nitrogen-containing heterocycles. Green Chem. Lett. Rev. 2013, 6:2, 151-182. DOI: 10.1080/17518253.2012.733032.

7. Silva, F. A. N.; Galluzzi, M. P.; Albuquerque, B.; Pizzuti, L.; Gressler, V.; Rivelli, D. P.; Barros, S. B. M. \& Pereira, C. M. P. Ultrasound irradiation promoted largescale preparation in aqueous media and antioxidant activity of azoles. Lett. Drug Des. Discov. 2009, 6, 323-326. DOI: 10.2174/1570180810906050323

8. Cravotto, G. and Cintas, P. The Combined Use of Microwaves and Ultrasound: Improved Tools in Process Chemistry and Organic Synthesis. Chem. Eur. J. 2007, 13, 1902-1909. DOI: 10.1002/chem.200601845.

9. Al-Mutairi, A. A.; El-Baih, F. E. M. \& Al-Hazimi, H. M. Microwave versus ultrasound assisted synthesis of some new heterocycles based on pyrazolone moiety. J. Saudi Chem. Soc. 2010, 14, 287-299. DOI: 10.1016/j.jscs.2010.02.010

10. Tiwari, V.; Parvez, A.; Meshram, J. Benign methodology and improved synthesis of 5-(2-chloroquinolin-3yl)-3-phenyl-4,5-dihydroisoxazoline using acetic acid aqueous solution under ultrasound irradiation. Ultrasonics Sonochem. 2011, 18, 911-916. DOI: 10.1016/j.ultsonch.2010.12.003.

11. Narlawar, R.; Pickhardt, M.; Leuchtenberger, S.; Baumann, K.; Krause, S.; Dyrks, T.; Weggen, S.; Mandelkow, E.; Schmidt, B. Curcumin-Derived Pyrazoles and Isoxazoles: Swiss Army Knives or Blunt Tools for Alzheimer's Disease? Chem. Med. Chem. 2008, 3, 165-172. DOI:10.1002/cmdc.200700218.

(C) 2017 by the authors. Submitted for possible open access publication under the terms and conditions of the Creative Commons Attribution (CC BY) license (http://creativecommons.org/licenses/by/4.0/). 